\title{
A COMPARISON OF THE PHRASEOLOGICAL STOCK OF BULGARIAN AND RUSSIAN (DEVELOPMENT AND PROBLEMS)
}

STEFKA GEORGIEVA

PLOVDIV UNIVERSITY PAISII HILENDARSKI

stefka3@abv.bg

The study makes a scientific comparison between the Bulgarian and the Russian phraseological stock as reflected in the works of linguists. Two stages in the development of phraseological nomination are studied in a synchronic perspective: 1) the period encompassing the Bulgarian National Revival and continuing into the $20^{\text {th }}$ and the early $21^{\text {st }}$ century, and 2) the period since the global changes which continues to the present days. Conclusions are drawn about the great extent of similarity of the phraseological stocks of Bulgarian and Russian and the extralinguistic changes in the phrases borrowed into the two languages. The connection between phrasemes and the nature and the culture of a nation, as well as the social and other factors influencing the phraseological stock of the particular languages is brought into focus.

Keywords: phrasemes, phraseological stock, national specifics, ethno-cultural information, picture of the world, neologisms, Bulgarian language, Russian language

\section{REFERENCES}

Alefirenko 2008: Alefirenko, N. F. Frazeologiia v svete sovremennykh ligvisticheskikh paradigm. Moskva, Elpis.

Arkhangelskiǐ 1978: Arkhangelskil, V. L. Semantika frazemnogo znaka. - In: Problemy russkoĭ frazeologii. Tula, Tulgospedinstitut im. L.N. Tolstogo.

Chlebda 2017: Chlebda, $W$. Slownikowy opis zwrotu cyfrowego. PodelśCie Pierwsze. Podręczny idiomatykon polsko-rosyjski / pod redakcją Wojciecha Chlebdy. Zeszyt 9. - Opole: Uniwersytet Opolski.

FS 2010: Frazeologicheskiĭ slovar' staroslavianskogo iazyka: svishe 500 edinits. Otv. redaktor S. G. Shulezhkova. Moskva, Flinta: Nauka.

Gak 1999: Gak, V. G. Natzional'no-kul'turnaia spetsifika meronimicheskikh frazeologizmov. - In: Frazeologiia v kontekste kul'tury. Moskva, Iazyki russkoi kul'tury.

Georgieva 2002: Georgieva, S. Problemy sopostavleniia russkoĭ frazeologii s bolgarskoľ. - In: Russkii iazyk "Problemy istorii, teorii i metodiki prepodavaniia". Shumen, Shumenski universitet.

Georgieva 2011: Georgieva, S. Russkaia frazeologiia v zerkale bolgarskogo iazyka. Sofia, Heron Press.

Dilevski 1979: Dilevski, N. Osnovni osobenosti na savremenniya balgarski knizoven ezik (sapostavitelno s ruski ezik). - In: Pomagalo po balgarska leksikologiya. Sofia, Nauka i izkustvo. 
Dimitrova 1996: Dimitrova, S. P. Frazeologizmy s opornym slovom „Bog“ v russkom c bolgarskom iazykakh. - Sapostavitelno ezikoznanie XXII, № 1.

Kirillova 1996: Kirillova, N. N. Istoki idioetnicheskoř teorii frazeologii. - In: Problemy idioetnicheskoř frazeologii. Sankt-Peterburg, Obrazovanie.

Koshelev, Leonidova 1974: Koshelev, A., M. Leonidova. Rusko-balgarski frazeologichen rechnik. Sofia - Moskva, Nauka i izkustvo - Ruski ezik.

Kyuvlieva 1986: Kyuvlieva, . Ustoychivite sravneniya v balgarskiya ezik. Sofia, Izd. na BAN.

Leonidova, Mokienko 1986: Leonidova, M. A., V. M. Mokienko. Russkaia frazeologiia v sopostavlenii s bolgarskol̆. - Bolgarskaia rusistika, № 6 .

Mokienko 2003: Mokienko, V. M. Novaia russkaia frazeologiia. - Opole, Uniwersytet Opolski - Instytut Filologii Polskej.

Mokienko und andere 2004: Mokienko, V., T. Malinski, L. Stepanova, H. Walter. Russishe Pfraseologie fur Deutsche der Slawistik. Greiswald, Uniwersytet Greiswald.

Nicheva 1987: Nicheva, K. Balgarska frazeologiya. Sofia, Nauka i izkustvo.

Petrova 2000: Petrova, G. Strukturno-semanticheskaia organizatsiia i funktsionirovanie frazeologizmov s arkhaicheskim komponentom v sovremennom russkom iazyke (s pozitsii nositelia bolgarskogo iazyka). Avtoref. dis. kand. fil. nauk. Moskva, In-t russk. Iaz. Im. A.S. Pushkina.

Pavlova 1979: Pavlova, R. Bolgarsko-russkie i russko-bolgarskie iazykovye sviazi. Sofia, Narodna prosveta.

Rusek 2002: Rusek, Z. Vliianie russskogo iayka na bolgarskiı̌. - In: III Slavisticheskie chteniia pamiati professora P. A. Dmitrieva i prof. G. I. Safonova. SanktPeterburg, $\mathrm{SPb}$ un-ta.

Saidova 1992: Saidova, S. E. Somaticheskie frazeologizmy russkogo i bolgarskogo iazykov. Baku, Avtoref. kand. dis. filol. nauk.

Shulezhkova 2018: Shulezhkova S. G. Ne smeshite moi podkovy: Slovar' krilatykh virazheniǐ iz multfilmov. Magnitogorsk, Magnitogorskij gos. Tehnicheskij universitet im. G. I. Nosova.

Stoianova 2002: Stoianova, E. Ustarevshie frazeologizmy russkogo iazyka i ikh bolgarskie ekvivalenty. Moskva, Avtoref. kand. dis. filol. nauk.

Tencheva 2017: Tencheva, B. Frazeologizmite v reklamnite tekstove (varhu material ot ruski ezik v sapostavka s balgarski i nemski ezik). Plovdiv, Avtoref. dokt. dis., PU.

Vlahov et al. 1980: Vlahov, S., K. Andreychina, St. Dimitrova, Kl. Zapryanova. Rusko-balgarski frazeologichen rechnik. Pod red. na S.I. Vlahov. Sofia Moskva, Nauka i izkustvo - Ruski ezik.

Vlahov et al. 1994: Vlahov, S., A. Georgieva, G. Gochev, S. Gocheva, E. PrevishKvinto, T. Tomeva, I. Hristova, D. Shkodrova. Pod red. na S. Vlahov. Ruskobalgarski tematichen rechnik na frazeologizmite. V. Tarnovo, VTU.

Voinova 1978: Voinova, S. Sravnitel'nyı̆ analiz frazeologicheskikh edinits s komponentami-tsvetooboznacheniiami (na materiale russkogo i bolgarskogo iazykov). Avtoref. diss. kand. filol. nauk. Leningrad, LGU. 
Zukov, Zukova 2009: Zukov, A. V., M. E. Zukova. Sovremennyı̆ frazeologicheskiū slovar' russkogo iazyka: ok. 1600 frazeologicheskikh edinits. - Moskva, AST: Astrel'.

$\triangle$ Prof. Stefka Georgieva, PhD

Faculty of Philology, Plovdiv University Paisii Hiledarski 24, Tsar Asen Str., 4000 Plovdiv, Bulgaria 